\title{
Analysis and comparison of spatial interpolation methods for temperature data in Xinjiang Uygur Autonomous Region, China
}

\author{
Huixia Chai ${ }^{1 *}$, Weiming Cheng ${ }^{1}$, Chenghu Zhou ${ }^{1}, \mathrm{Xi} \mathrm{Chen}^{2}, \mathrm{Xiaoyi} \mathrm{Ma}^{1}$, Shangming Zhao ${ }^{2}$ \\ ${ }^{1}$ State Key Laboratory of Resources and Environmental Information System, Institute of Geographic Sciences and Natural Resources \\ Research CAS, Beijing, China; ${ }^{*}$ Corresponding Author: chaihx@1reis.ac.cn \\ ${ }^{2}$ Xinjiang Institute of Ecology and Geography CAS, Urumqi, China.
}

Received 24 October 2011; revised 20 November 2011; accepted 7 December 2011.

\section{ABSTRACT}

Spatial interpolation methods are frequently used to estimate values of meteorological data in locations where they are not measured. However, very little research has been investigated the relative performance of different interpolation methods in meteorological data of Xinjiang Uygur Autonomous Region (Xinjiang). Actually, it has importantly practical significance to as far as possibly improve the accuracy of interpolation results for meteorological data, especially in mountainous Xinjiang. Therefore, this paper focuses on the performance of different spatial interpolation methods for monthly temperature data in Xinjiang. The daily observed data of temperature are collected from 38 meteorological stations for the period 1960 2004. Inverse distance weighting (IDW), ordinary kriging (OK), temperature lapse rate method (TLR) and multiple linear regressions (MLR) are selected as interpolated methods. Two rasterized methods, multiple regression plus space residual error and directly interpolated observed temperature (DIOT) data, are used to analyze and compare the performance of these interpolation methods respectively. Moreover, cross-validation is used to evaluate the performance of different spatial interpolation methods. The results are as follows: 1) The method of DIOT is unsuitable for the study area in this paper. 2) It is important to process the observed data by local regression model before the spatial interpolation. 3) The MLR-IDW is the optimum spatial interpolation method for the monthly mean temperature based on cross-validation. For the authors, the reliability of results and the influence of measurement accuracy, density, dis- tribution and spatial variability on the accuracy of the interpolation methods will be tested and analyzed in the future.

Keywords: Spatial Interpolation Method; Cross validation; Monthly Mean Temperature; Xinjiang Uygur Autonomous Region

\section{INTRODUCTION}

Many researchers in different countries or various organizations from all over the world have put much effort into interpolating the meteorological data [1-9]. Measurements of meteorological data (e.g. temperature, humidity, wind speed and rainfall) at higher resolution are available only at limited stations because meteorological data are generally recorded at specific locations and derived from different meteorological stations. Moreover, the essence of the spatial interpolation is to transfer available information in the form of data from a number of adjacent irregular sites to the estimated sites through a function that represents the spatial weights according to the distances between the sites [10]. For these reasons, spatial interpolation methods are frequently used to estimate values of meteorological data in locations where they are not measured [11]

Although a variety of deterministic and geo-statistical interpolation methods are available to estimate variables at un-sampled locations, accuracies vary widely among methods [12]. The quality of climate spatial interpolation depends on the spatial variation of climate factors, the spatial distribution of climate stations, and the interpolation method $[13,14]$. Consequently, many researchers try to compare different spatial interpolation methods based on different climate factors in various areas [15-19]. All of these researches discussed various spatial interpolation methods (including basic principle, application and 
precision) of meteorological elements, valuable conclusions were reached that the optimum spatial interpolation method of one climate factor could not be suitable for the other climate factors in the same area or the same climate factor in different areas.

Actually, it is more difficult and important to build climate layers as a result of sparse meteorological stations and complex topography [20]. Moreover, the optimal spatial interpolation methods for various spatial variables less appear and are applicable to the specific conditions [21-25]. In different regions and various temporal-spatial scales, the so-called "optimal" interpolation is relatively. In other words, no one spatial interpolation method is the absolutely optimal method due to the features of interpolation method (e.g. hypothesis, temporal-spatial scale, algorithm, and attributes of data).

Xinjiang Uygur Autonomous Region is located in the inner center of Eurasia. It is the core region of the arid land in the northwest China. Xinjiang Uygur Autonomous Region has been one of the hot-spot areas in geographic research [26-34] due to its unique geomorphologic features and important geographic location. However, only few researchers focused on seeking effective methods of spatial interpolation for temperature [35-37] and rainfall [38] in Xinjiang. Moreover, the conclusion about the optimal method for temperature in Xinjiang is different according to the research results of the above mentioned literatures.

Therefore, the main objective of this paper is to find out which one is the optimal interpolation method for monthly mean temperature in Xinjiang Uygur Autonomous Region. Firstly, temperature data of Xinjiang from many years are used to compare the performance of four spatial interpolation methods, such as, Inverse distance weighting, Ordinary kriging, Temperature lapse rate method and Multiple linear regression with regard to their errors by cross-validation. Secondly, two rasterized methods (multiple regression plus space residual error, direct interpolation with observed data of temperature) are adopted to illustrate quality of spatial interpolation methods. Finally, the conclusion as to which method is significantly better than others on the basis of $\mathrm{MBE}$, MAE, and RMSE is proposed

\section{METHOD AND MATERIAL}

\subsection{Study Area}

The study area of this research is Xinjiang Uygur Autonomous Region, lying in the middle of Asia's continental shelf. It is located between $34^{\circ} \sim 50^{\circ} \mathrm{N}, 75^{\circ} \sim$ $97^{\circ} \mathrm{E}$, northwest of China (Figure 1). The Xinjiang's climate is mainly controlled by three factors: geographical location (far away from the ocean), terrain structure (mountain and basin) and the Qinghai-Tibet Plateau [39].

The basic geomorphologic pattern of Xinjiang in and abroad is the direct cause of local climate. The Himalayas

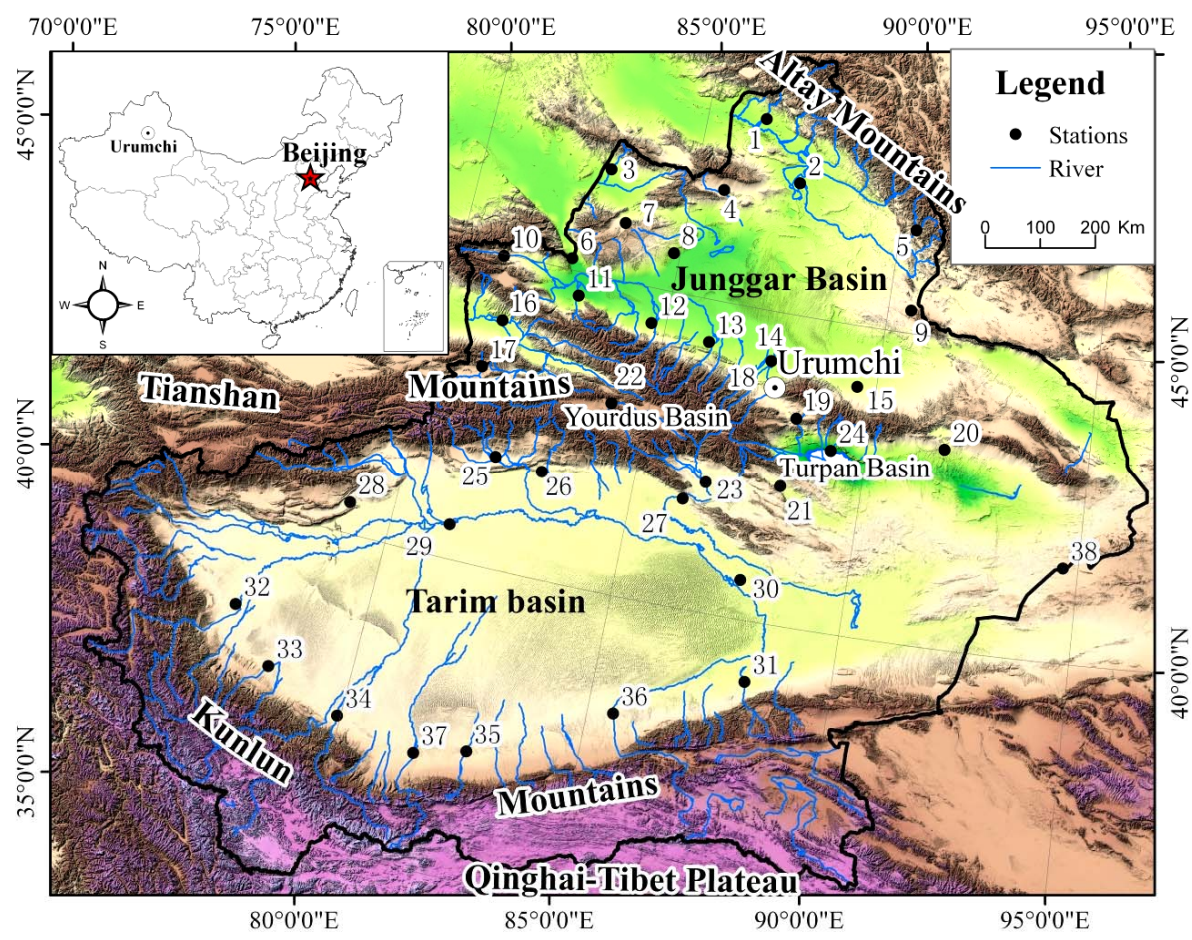

Figure 1. Study area and the distribution of meteorological stations. 
and Qinghai-Tibet Plateau block the southwest monsoon from the Indian Ocean with rich content of water vapor. The southeast monsoon from Pacific Ocean has little chance to reach Xinjiang, because it is obstructed by circumambient mountains such as Qinling Mountains, Greater Hinggan Mountains, Qilian Mountain, and Qinghai-Tibet Plateau. The north air current from Arctic Ocean usually pass through Altay Mountains and can arrive in Xinjiang. But it mainly distributes in the north of Xinjiang. Moreover, it can form less rainfall because the air current from Arctic Ocean belongs to dry and cold air with poor content of water. Temperature of southern Xinjiang is higher than that of northern Xinjiang. According to the latitude zones, southern Xinjiang and northern Xinjiang belong to warm temperate zone and temperate zone respectively. The zone differentiation becomes enhancement due to the blocking of Tianshan Mountains. The annual frost-free period is about 200 - 220 days in plain area of southern Xinjiang, however, it is about 150 days in northern Xinjiang [39].

\subsection{Data}

The main data source of this paper includes meteorological data and SRTM-DEM.

In this article, daily observed data are collected from 54 meteorological stations in Xinjiang during the period 1951-2009. These meteorological stations are both National basic stations and province benchmark stations. In all, 38 meteorological stations for the period 1960-2004 are picked out after analyzing and quality control procedure based on Microsoft Office Access and Geographic information system (GIS). The distribution of 38 meteorological stations is showed in the Figure 1.

The Shuttle Radar Topography Mission digital elevation model (SRTM-DEM) (USGS, 2004) is used to extract the elevation value in this article. The resolution of SRTM-DEM data is $90 \times 90 \mathrm{~m}$.

\subsection{Methodology}

In recent years, some researchers developed many modified interpolation methods $[10,13,35,40]$. Based on the rasterized method of temperature data, most researches show that method of "multiple regression plus space residual error" is better than that of "directly interpolated for observe data of temperature" $[36,37,41]$. For the study area, IDW, Ordinary Kriging (OK), Temperature lapse rate method (TLR), and Multiple linear regression (MLR) are selected in this article to compare their performance for monthly mean temperature. IDW and $\mathrm{OK}$ are used to directly interpolate observed data of temperature. TLR and MLR are used to interpolate revisionary data. That means observed data should be re- vised by regression formula before interpolating. The following is briefly introduction of interpolation methods used in this study.

1) Inverse Distance Weighting. The IDM value is given by the following formula.

$$
T\left(s_{0}\right)=\sum_{i=1}^{38} \beta_{i} T\left(s_{i}\right)
$$

In Formula 1, $T\left(s_{0}\right)$ is predicted value of $s_{0}$ (predicted point), $\beta_{i}$ is power coefficient of sampled points, $T\left(s_{i}\right)$ is observed value of $s_{i}$ (sampled point).

2) Ordinary Kriging. The method is expressed as following formula.

$$
Z\left(s_{0}\right)=\sum_{i=1}^{n} \lambda_{i} Z\left(s_{i}\right)
$$

In the Formula 2, the weight is derived from the Kriging system in following formula $(i=1,2, \cdots, n)$.

$$
\left\{\begin{array}{l}
\sum_{i=1}^{n} \lambda_{i} \gamma\left(s_{i}-s_{j}\right)+\mu=\gamma\left(s_{i}-s_{0}\right) \\
\sum_{i=1}^{n} \lambda_{i}=1
\end{array}\right.
$$

3) Temperature lapse rate method (TLR) can use following formulate.

$$
\begin{gathered}
\left\{\begin{array}{l}
T_{s}=T_{o}+b H_{o} / 100 \\
T_{e}=T_{s}-b H_{d} / 100
\end{array}\right. \text { (No elevation error) } \\
\left\{\begin{array}{l}
T_{s}^{\prime}=T_{o}+b H_{d} / 100 \\
T_{e}^{\prime}=T_{s}^{\prime}-b H_{d} / 100
\end{array}\right. \text { (With elevation error) } \\
\Delta T=T_{e}-T_{e}^{\prime}
\end{gathered}
$$

In Formula 4, Formula 5 and Formula $6, T_{s}\left(T_{s}^{\prime}\right)$ is revisionary temperature of the virtual sea level $\left({ }^{\circ} \mathrm{C}\right), T_{o}$ is observed temperature of meteorological station $\left({ }^{\circ} \mathrm{C}\right), b$ is temperature lapse rate, $T_{e}\left(T_{e}^{\prime}\right)$ is estimated temperature $\left({ }^{\circ} \mathrm{C}\right), H_{o}$ is observed elevation of meteorological station (m), $H_{d}$ is elevation value from DEM of point which has the same coordinates with that of meteorological station (m), $\Delta T$ is difference between $T_{e}$ and $T_{e}^{\prime}\left({ }^{\circ} \mathrm{C}\right)$.

4) Multiple Linear Regression (MLR). Firstly, regression formula with elevation, latitude, and longitude is built.

$$
T=a H+b L a+c L o+E
$$

In Formula 7, $T$ is temperature, $a, b, c$ are regression coefficients, $H$ is elevation, $L a$ is latitude, $L o$ is longitude, $E$ is residual error. Least-square method is used to obtain parameters, such as $a, b, c, E$. The equations set are expressed as follows. 


$$
\left\{\begin{array}{l}
\sum T=n E+a \sum H+b \sum L a+c \sum L o \\
\sum T H=E \sum H+a \sum H+b \sum H^{2}+b \sum H L a+c \sum H L o \\
\sum T L a=E \sum L a+a \sum H L a+b \sum L a^{2}+c \sum L a L o \\
\sum T L o=E \sum L o+a \sum H L o+b \sum L a L o+c \sum L o^{2}
\end{array}\right.
$$

The following matrix is used to obtain parameters value.

$$
\begin{aligned}
& B=\left(x^{\prime} x\right)^{-1} \cdot\left(x^{\prime} y\right)
\end{aligned}
$$

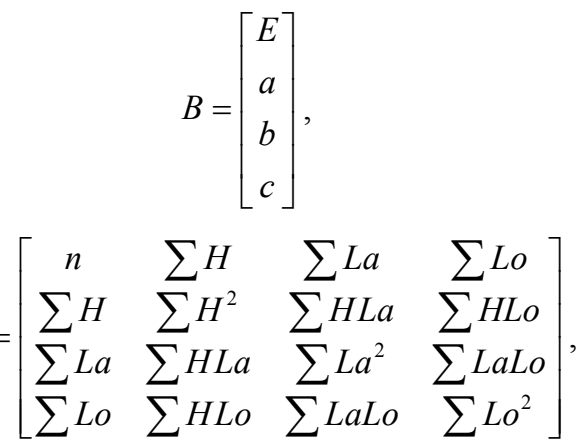

$$
\begin{aligned}
& \begin{array}{c}
B=\left[\begin{array}{l}
E \\
a \\
b \\
c
\end{array}\right], \\
\left(x^{\prime} x\right)=\left[\begin{array}{cccc}
n & \sum H & \sum L a & \sum L o \\
\sum H & \sum H^{2} & \sum H L a & \sum H L o \\
\sum L a & \sum H L a & \sum L a^{2} & \sum L a L o \\
\sum L o & \sum H L o & \sum L a L o & \sum L o^{2}
\end{array}\right],
\end{array} \\
& \left(x^{\prime} y\right)=\left[\begin{array}{c}
\sum T \\
\sum T H \\
\sum T L a \\
\sum T L o
\end{array}\right]
\end{aligned}
$$

Secondly, Eq.7 and SRTM-DEM are used to estimate the temperature of study area. The output data is named estimated temperature $\left(\hat{T}_{e}\right)$.

Thirdly, interpolation residual error $E$ is analyzed. The interpolation method includes IDW and OK. The output data is named residual error layer.

Finally, the estimated temperature $\left(T_{e}=\hat{T}_{e}+E\right)$ is gained through overlaying two data layers, that is, estimated temperature and residual error layer.

The most common one for assessing prediction errors of spatial interpolation methods is cross-validation. Generally, the mean/mean-biased error (ME or MBE), the mean absolute error (MAE), and the root mean squared error (RMSE) are used to estimate the error statistic. Other researchists use standardized RMSE as an additional measure to evaluate the uncertainty of Kriging statistics $[11,42]$. Consequently, cross-validation is used to evaluate the performance of different spatial interpolation methods in this paper. To describe the performance of interpolation methods, the deviations of validation results are summarized by three average error statistics methods, such as, RMSE, MAE and MBE (ME).

\subsection{Computational Details}

Spatial analyst tool and geostatistical analyst tool of
ArcGIS are used to interpolate and analyze temperature data in this paper.

Based on ArcGIS, the function of IDW has two options, that is, a fixed search radius type and a variable search radius type. In this study, the variable radius type is selected because sample points are sparse and randomly placed.

For Kriging method, cross validation techniques are used to choose spherical semivariogram model because it (spherical model) is widely used. In this search, radius is used as variable with default value.

To decide whether the model can be applied, it is necessary to verify and estimate multiple linear regression model after obtaining the regression parameters. The content and method for testing and estimating include fitting degree test (R-squared, $R^{2}$ ), standard deviation test $\left(S_{T}\right)$, and significance test $(F)$.

\section{RESULTS AND DISCUSSION}

\subsection{Meteorological Data}

The quality control procedure can ensure the continuity and effectiveness of data in our research. Daily observed data of temperature is collected from 54 meteorological stations for the period 1951-2009. After analyzing quality of meteorological data, $29.62 \%$ of stations are rejected because of missing data or short duration, $11.06 \%$ of the observed data is filtered out because of invalid data or unreasonable temporal sequence. The monthly mean temperature values of 38 meteorological stations area selected for the period 1960-2004.

Therefore, the number of stations is rare for the study area and their distribution is inordinate because of complex topography (Figure 1). Most stations locate in plain area. Few stations distribute in the intermountain basin of Tianshan Mountains. Other mountain areas have no stations. However, temperature in mountainous region decreases with the increasing of altitude. Moreover, deserts in the basin will affect temperature in plain area. Consequently, there exists the possible error between the interpolation result and observed temperature.

According to Figure 2, the minimum temperature appears in No. 22 of all meteorological stations in every month, and the highest temperature distributes in No. 24. This means the temperature of Yourdus Basin, located in middle Tianshan Mountains, is the lowest per month. Moreover, the temperature of Turpan Basin is the highest (Figure 1).

Table 1 shows the values of average, maximum, and minimum of monthly mean temperature for the period 1960-2004 in study area. According to the Table 1, the highest value of the maximum temperature is $32.39^{\circ} \mathrm{C}$ in July. The lowest value of the maximum temperature is 


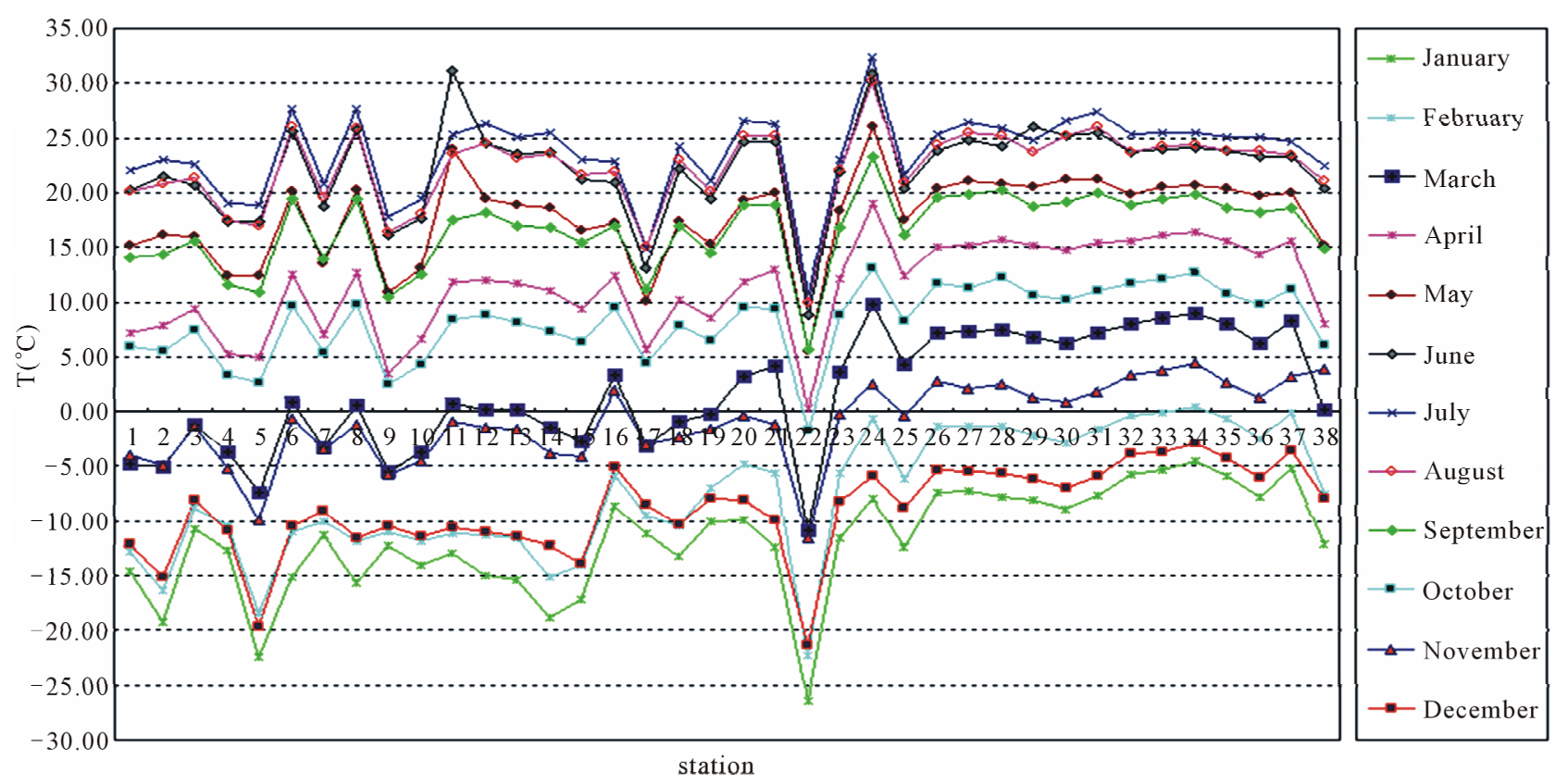

Figure 2. The line chart of monthly mean temperature.

Table 1. Monthly mean temperatures for the period 1960-2004 $\left({ }^{\circ} \mathrm{C}\right)$.

\begin{tabular}{ccccccc}
\hline Month & $\mathbf{1}$ & $\mathbf{2}$ & $\mathbf{3}$ & $\mathbf{4}$ & $\mathbf{5}$ & $\mathbf{6}$ \\
\hline $\mathrm{T}_{\max }$ & -4.51 & 0.48 & 9.75 & 19.08 & 26.05 & 31.08 \\
$\mathrm{~T}_{\min }$ & -26.46 & -22.31 & -10.92 & 0.34 & 5.51 & 8.90 \\
$\mathrm{~T}_{\text {average }}$ & -11.71 & -7.51 & 1.76 & 11.36 & 17.78 & 22.22 \\
\hline Month & $\mathbf{7}$ & $\mathbf{8}$ & $\mathbf{9}$ & $\mathbf{1 0}$ & $\mathbf{1 1}$ & $\mathbf{1 2}$ \\
\hline $\mathrm{T}_{\max }$ & 32.39 & 30.21 & 23.25 & 13.06 & 4.37 & -2.87 \\
$\mathrm{~T}_{\min }$ & 10.71 & 9.91 & 5.60 & -1.81 & -11.54 & -21.34 \\
$\mathrm{~T}_{\text {average }}$ & 23.63 & 22.31 & 16.65 & 8.23 & -0.94 & -8.95 \\
\hline
\end{tabular}

$-4.51^{\circ} \mathrm{C}$ in January. For the minimum temperature of monthly mean temperature, the maximum value is $10.71^{\circ} \mathrm{C}$ in July and the minimum value is $-26.46^{\circ} \mathrm{C}$ in January.

According the data sets, July is the hottest month and January is the coldest month. Therefore, monthly mean temperature of June, July and August is selected to stand for summer temperature, and monthly mean temperature of December, January and February to represent winter temperature in this study.

\subsection{Comparison of Interpolation Methods}

Spatial interpolation is an extremely important method for the spatial analysis of GIS. For a region with scarce and unreasonable distribution of observation stations, spatial interpolation is the basic method for studying the distribution of spatial variables. This is one of the premises to establish spatial model. Three ways are used to examine the performance of the interpolation methods above mentioned in this paper.

\subsubsection{Directly Interpolating Observed Temperature (DIOT)}

This section analyzes the performance of IDW and OK. These two methods are applied to interpolate the observed temperature directly.

According to Table 2, it is not a good idea to interpolate observed temperature directly for this study area. Obviously, the RMSE values of validation results by DIOT are too big.

The error values of calculation on the basis of the validation result (Table 2), both IDW and $\mathrm{OK}$, are too big. Consequently, it is not a good idea to interpolate the observed temperature data directly for Xinjiang. In other words, it is necessary to revise the observed data before implementing spatial interpolation.

\subsubsection{Temperature Lapse Rate Method (TLR)}

\subsubsection{Difference of Elevation}

TLR considers temperature will decrease with the increase of altitude. Table 3 shows the difference between elevation based on meteorological stations and elevation from corresponding SRTM-DEM. The biggest difference of elevation can reach up to $103.7 \mathrm{~m}$. The smallest difference of elevation is $0.2 \mathrm{~m}$. Moreover, the elevation differences of most stations are less than $10 \mathrm{~m}$. 
Table 2. Validation result of directly interpolate observed temperature (DIOT).

\begin{tabular}{ccccccc}
\hline \multirow{2}{*}{ Methods } & \multicolumn{3}{c}{ IDW } & & & OK \\
\cline { 2 - 7 } & ME & MAE & RMSE & ME & MAE & RMSE \\
\hline January & -1.30 & 27.31 & 38.21 & 1.76 & 27.87 & 40.69 \\
February & -1.85 & 25.50 & 38.43 & 2.69 & 27.11 & 40.77 \\
March & 0.44 & 25.32 & 35.87 & 2.16 & 25.25 & 38.07 \\
April & 1.82 & 24.83 & 35.04 & -0.06 & 25.98 & 36.16 \\
May & 2.57 & 27.28 & 38.79 & -2.11 & 34.41 & 43.90 \\
June & 3.11 & $\mathbf{3 0 . 5 0}$ & $\mathbf{4 2 . 6 8}$ & -2.31 & $\mathbf{3 5 . 5 3}$ & $\mathbf{4 7 . 0 5}$ \\
July & 2.01 & 28.02 & 39.16 & -3.12 & 33.81 & 43.38 \\
August & 2.01 & 26.17 & 36.86 & -1.11 & 32.70 & 41.67 \\
September & 1.82 & 23.66 & 33.16 & -1.16 & 28.46 & 36.84 \\
October & 1.30 & 20.70 & $\mathbf{2 8 . 8 9}$ & -0.23 & 25.74 & $\mathbf{3 3 . 4 7}$ \\
November & -0.60 & $\mathbf{1 9 . 7 9}$ & 29.14 & 2.18 & $\mathbf{1 9 . 6 8}$ & 30.15 \\
December & -0.23 & 20.44 & 31.76 & 2.23 & 21.82 & 34.44 \\
\hline
\end{tabular}

Table 3. The elevation difference between station and corresponding Srtm-DEM (m).

\begin{tabular}{ccccccccc}
\hline E_s & 1247.2 & 1409.5 & 935 & 2458 & 1375.4 & 1012.2 & 1357.8 & 1055.3 \\
E_d & 1247 & 1410 & 934 & 2459 & 1374 & 1014 & 1361 & 1059 \\
AE & 0.2 & 0.5 & 1 & 1 & 1.4 & 1.8 & 3.2 & 3.7 \\
E_s & 931.5 & 887.7 & 846 & 922.4 & 1218.2 & 1291.6 & 1161.8 & 1077.8 \\
E_d & 936 & 883 & 851 & 928 & 1213 & 1286 & 1156 & 1084 \\
AE & 4.5 & 4.7 & 5 & 5.6 & 5.2 & 5.6 & 5.8 & 6.2 \\
E_s & 1229.2 & 1103.5 & 500.9 & 1231.2 & 478.7 & 534.9 & 662.5 & 721.4 \\
E_d & 1223 & 1097 & 494 & 1224 & 471 & 543 & 675 & 712 \\
AE & 6.2 & 6.5 & 6.9 & 7.2 & 7.7 & 8.1 & 12.5 & 9.4 \\
E_s & 449.5 & 336.1 & 1081.9 & 320.1 & 442.9 & 532.6 & 1422 & 1375 \\
E_d & 459 & 326 & 1070 & 306 & 457 & 517 & 1438 & 1352 \\
AE & 9.5 & 10.1 & 11.9 & 14.1 & 14.1 & 15.6 & 16 & 23 \\
E_s & 34.5 & 1851 & 440.5 & 793.5 & 1573.8 & 1653.7 & & \\
E_d & 9 & 1877 & 467 & 762 & 1541 & 1550 & & \\
AE & 25.5 & 26 & 26.5 & 31.5 & 32.8 & 103.7 & & \\
\hline
\end{tabular}

Based on the altitude value of meteorological stations, the relatively poor precision of altitude value of SRTMDEM is the cause of the elevation difference. It means that the coordinate difference result in the elevation difference between stations and SRTM-DEM, which could produce a larger error in the process of interpolation.

Generally, the elevation data from the meteorological departments is theoretically accurate than SRTM-DEM. Because the elevation from SRTM-DEM is derived from the rasterized process of temperature data and the amount of meteorological stations is very limited comparing for the whole study area. Therefore, it is worthy of analyzing the elevation from meteorological departments or from SRTM-DEM during establishing regres- 
sion equations.

\subsubsection{Validation Result}

According to the research of Yang [43], the change of temperature in study area is different between summer and winter. The temperature will reduce $6^{\circ} \mathrm{C}-8^{\circ} \mathrm{C}$ when the altitude increase each $1000 \mathrm{~m}$ in summer. In winter season, the temperature will rises $3^{\circ} \mathrm{C}-5^{\circ} \mathrm{C}$ with the increase of altitude per $1000 \mathrm{~m}$. According to the experiences and research results of other researchers [43, 44], this paper uses the average value as the temperature lapse rate which is $0.7^{\circ} \mathrm{C} / 100 \mathrm{~m}$ in summer (monthly mean temperature of July), and $-0.4^{\circ} \mathrm{C} / 100 \mathrm{~m}$ in winter (monthly mean temperature of January). Consequently, this paper uses monthly mean temperature of six month (December, January, February, June, July and August) to test the performance of TLR.

Table 4 indicates that the result precision based on the elevation from meteorological departments is slightly higher than the result precision based on the elevation from corresponding SRTM-DEM. Other researchers also have similar results $[41,44]$. Consequently, the difference of elevation between meteorological stations and corresponding SRTM-DEM is not significant.

For the monthly mean temperature of December, January and February, the RMSE values of IDW are greater than the RMSE values of OK. Contrarily, the RMSE values of IDW are less than the RMSE values of OK for the monthly mean temperature of June, July and August. This means TLR_OK is better than TLR_IDW for the interpolation of winter monthly mean temperature. It is a good idea to use TLR_IDW for the interpolation of summer monthly mean temperature.

\subsubsection{Multiple Linear Regression (MLR)}

\subsubsection{Correlation Coefficient}

Table 5 shows the results of correlation coefficients, R-squared $\left(R^{2}\right)$, Standard deviation $\left(S_{T}\right)$ and significance test of regression equation (F-test). These correlation coefficients are used for MLR. They can help the author to estimate the applicability of the multiple linear regression models.

From the Table 5, all of $R^{2}$ values are bigger than 0.5 and most of $R^{2}$ values are higher than 0.7 except for those of January and December. It means that there exist certain linear correlation between temperature and altitude, latitude and longitude. From these tables, the biggest $R^{2}$ appears in April. The $R^{2}$ value of January is the smallest. According to the rule: the value of $R^{2}$ is closer to 1.0 if the model is closer to reality. So the multiple linear regression models in April, May, July and August are closer to reality.

Collins [45] thought that the goal using polynomial regression is to obtain the best fit and the simplest model. He pointed that the addition of regressor variables which do not contribute significantly to the model has the unwanted effect of increasing multicollinearity [45]. Multicollinearity may negatively affect the model's ability to predict outside the convex hull of data points [46].

Table 4. Validation result of TLR.

\begin{tabular}{|c|c|c|c|c|c|c|c|}
\hline \multirow{2}{*}{\multicolumn{2}{|c|}{ Methods }} & \multicolumn{3}{|c|}{ Based on observed altitude } & \multicolumn{3}{|c|}{ Based on DEM altitude } \\
\hline & & 12 & 1 & 2 & 12 & 1 & 2 \\
\hline \multirow{3}{*}{ IDW } & $\mathrm{ME}$ & 0.18 & 0.08 & 0.02 & 0.18 & 0.07 & 0.02 \\
\hline & MAE & 2.69 & 3.16 & 3.29 & 2.70 & 3.18 & 3.29 \\
\hline & RMSE & 4.39 & 4.84 & 5.08 & 4.40 & 4.86 & 5.09 \\
\hline \multirow{3}{*}{$\mathrm{OK}$} & $\mathrm{ME}$ & -0.26 & -0.22 & -0.26 & -0.25 & -0.24 & -0.27 \\
\hline & MAE & 3.23 & 3.67 & 4.13 & 3.23 & 3.72 & 4.14 \\
\hline & RMSE & 4.85 & 5.38 & 5.85 & 4.87 & 5.42 & 5.86 \\
\hline \multicolumn{2}{|c|}{ Methods } & 6 & 7 & 8 & 6 & 7 & 8 \\
\hline \multirow{3}{*}{ IDW } & $\mathrm{ME}$ & -0.10 & -0.25 & -0.16 & -0.11 & -0.17 & -0.15 \\
\hline & MAE & 1.53 & 1.36 & 1.37 & 1.31 & 1.26 & 1.33 \\
\hline & RMSE & 1.88 & 1.57 & 1.58 & 1.74 & 1.50 & 1.55 \\
\hline \multirow{3}{*}{$\mathrm{OK}$} & $\mathrm{ME}$ & 0.01 & -0.08 & -0.03 & 0.01 & -0.08 & -0.03 \\
\hline & MAE & 1.40 & 1.26 & 1.30 & 1.34 & 1.19 & 1.25 \\
\hline & RMSE & 1.77 & 1.47 & 1.48 & 1.74 & 1.43 & 1.44 \\
\hline
\end{tabular}


Table 5. The correlation coefficients of MLR.

\begin{tabular}{ccccccc}
\hline \multirow{2}{*}{ Month } & \multicolumn{3}{c}{ Based on observed altitude } & \multicolumn{2}{c}{ Based on Srtm-DEM altitude } \\
\cline { 2 - 6 } & $R^{2}$ & $S_{T}$ & F-test & $R^{2}$ & $S_{T}$ & F-test \\
\hline January & 0.56 & 3.37 & 14.52 & 0.57 & 3.35 & 14.78 \\
February & 0.70 & 3.29 & 26.67 & 0.71 & 3.28 & 27.12 \\
March & 0.87 & 1.99 & 76.98 & 0.87 & 1.97 & 78.79 \\
April & 0.94 & 1.13 & 163.51 & 0.94 & 1.12 & 166.71 \\
May & 0.92 & 1.19 & 132.07 & 0.93 & 1.15 & 142.15 \\
June & 0.88 & 1.53 & 83.01 & 0.89 & 1.48 & 90.16 \\
July & 0.91 & 1.23 & 113.69 & 0.91 & 1.19 & 121.28 \\
August & 0.90 & 1.23 & 102.06 & 0.90 & 1.21 & 106.44 \\
September & 0.89 & 1.19 & 96.28 & 0.90 & 1.17 & 99.54 \\
October & 0.89 & 1.15 & 91.34 & 0.89 & 1.13 & 94.41 \\
November & 0.73 & 1.99 & 31.20 & 0.74 & 1.98 & 31.88 \\
December & 0.62 & 2.65 & 18.12 & 0.62 & 2.64 & 18.44 \\
\hline
\end{tabular}

According to the Table 5, there exist certain linear correlation between temperature and altitude, latitude and longitude. Through considering the significance test of regression equation (F-test), this paper adopts 0.05 as the significant level $(a)$ and finds the corresponding critical value by checking the $\mathrm{F}$ distribution list.

$$
F_{0.05}(3,40)=2.84<F_{0.05}(3,34)<2.92=F_{0.05}(3,30)
$$

For this study, significant level $(a)$ is $1 \%$, and freedom is $(3,34)$. If $F>F_{a}$, it means that the regression equation is significant and its effect is remarkable. If $F<F_{a}$, it means that the regression equation is not significant and available. It is obviously (Table 5) that all values of $F_{i}(i=1,2, \cdots, 12)$ are much greater than that of $F_{0.05}(3$, $34)$. This means the regression equations are significant and effective.

\subsubsection{Validation Result}

For the interpolation method of MLR, there exists slightly difference between the predicted results possessing elevation error and that of non-possessing elevation error (Tables 6 and 7). 1) If the predicted results possess elevation error, the RMSE values of MLR-IDW are greater than the RMSE values of MLR-OK in winter (the monthly mean temperature of December, January and February). For other months, the RMSE values of MLR-IDW are less than those of MLR-OK. 2) If the predicted results do not possess elevation error, the RMSE values of MLR-OK are less than those of MLRIDW in December, January, February and April. For other months, the RMSE values of MLR-IDW are less than those of MLR-OK. 3) Nonetheless, these differences are slight. The method of MLR-IDW is a little bit better than that of MLR-OK for the study area. Therefore, the elevation difference between meteorological stations and corresponding SRTM-DEM is not significant.

\subsubsection{Summary of the Discussion}

Table 8 shows the briefly summary of characteristics on IDW, OK, TLR and MLR. The performances of these methods in this study show the following characteristics:

1) From the point of view of the predicted error, the methods of MLR and TLR have advantages than that of DIOT. TLR and MLR significantly weaken the predicted error of monthly mean temperature.

2) However, according to the computational complexity, DIOT-IDW and DIOT-OK are better than other methods. From easy to complex, the order of these methods is DIOT, TLR and MLR based on the complexity of data processing. This order also shows that the calculation amount of these methods from small to large.

3) Moreover, the order of these methods is DIOTIDW, TLR_IDW, MLR-IDW, DIOT-OK, TLR_OK and MLR-OK based on their computational speed.

Obviously, spatial interpolation for meteorological data between Xinjiang and other general areas are different. In order to obtain optimal result of spatial interpolation, other factors, such as elevation, latitude and longitude are used to rectify the observed data. This is a necessary and advisable process before realizing spatial interpolation, because the number of meteorological 
Table 6. Validation result of MLR based on observed altitude.

\begin{tabular}{ccccccc}
\hline \multirow{2}{*}{ Methods } & \multicolumn{3}{c}{ MLR-IDW } & & \multicolumn{3}{c}{ MLR-OK } \\
\cline { 2 - 7 } & ME & MAE & RMSE & ME & MAE & RMSE \\
\hline January & 0.006 & 1.295 & 1.605 & 0.097 & 1.100 & 1.510 \\
February & -0.030 & 1.752 & 2.178 & 0.129 & 1.496 & 2.052 \\
March & 0.070 & 2.322 & 2.988 & 0.186 & 2.197 & 3.028 \\
April & 0.122 & 2.558 & 3.348 & 0.092 & 2.450 & 3.307 \\
May & 0.240 & 2.710 & 3.695 & -0.115 & 3.152 & 4.015 \\
June & 0.288 & 2.923 & 4.022 & -0.006 & 3.402 & 4.397 \\
July & 0.246 & 2.699 & 3.717 & -0.089 & 3.239 & 4.141 \\
August & 0.221 & 2.525 & 3.466 & -0.116 & 2.993 & 3.810 \\
September & 0.146 & 2.374 & 3.161 & -0.043 & 2.673 & 3.390 \\
October & 0.151 & 1.911 & 2.543 & 0.057 & 1.935 & 2.612 \\
November & 0.054 & 1.533 & 1.979 & 0.123 & 1.464 & 2.018 \\
December & 0.032 & 1.263 & 1.589 & 0.098 & 1.123 & 1.545 \\
\hline
\end{tabular}

Table 7. Validation result of MLR based on Srtm-DEM altitude.

\begin{tabular}{ccccccc}
\hline \multirow{2}{*}{ Mehodts } & \multicolumn{3}{c}{ MLR-IDW } & & \multicolumn{3}{c}{ MLR-OK } \\
\cline { 2 - 6 } & ME & MAE & RMSE & ME & MAE & RMSE \\
\hline January & 0.007 & 1.324 & 1.646 & 0.101 & $\mathbf{1 . 1 4 0}$ & $\mathbf{1 . 5 6 5}$ \\
February & -0.032 & 1.776 & 2.214 & 0.134 & 1.533 & 2.101 \\
March & 0.064 & 2.337 & 3.010 & 0.190 & 2.225 & 3.060 \\
April & 0.181 & 2.448 & 3.300 & 0.094 & 2.464 & 3.325 \\
May & 0.233 & 2.729 & 3.720 & -0.094 & 3.190 & 4.074 \\
June & 0.280 & $\mathbf{2 . 9 5 2}$ & $\mathbf{4 . 0 5 6}$ & -0.069 & $\mathbf{3 . 4 8 0}$ & $\mathbf{4 . 5 1 1}$ \\
July & 0.238 & 2.721 & 3.741 & -0.110 & 3.214 & 4.102 \\
August & 0.214 & 2.538 & 3.485 & -0.181 & 3.032 & 3.862 \\
September & 0.182 & 2.254 & 3.057 & -0.053 & 2.695 & 3.414 \\
October & 0.146 & 1.920 & 2.558 & 0.056 & 1.953 & 2.632 \\
November & 0.052 & 1.548 & 2.001 & 0.127 & 1.488 & 2.048 \\
December & 0.031 & $\mathbf{1 . 2 8 3}$ & $\mathbf{1 . 6 1 7}$ & 0.101 & 1.152 & 1.583 \\
\hline
\end{tabular}

stations in Xinjiang is sparse, and partly areas in Xinjiang without any data especially.

The RMSE values of MLR are worse than those of TLR in winter. Conversely, The RMSE values of MLR are greater than those of TLR in summer.

In general, MLR-IDW is the most suitable predicted method for the monthly mean temperature of winter season and TLR-OK is propitious for the monthly mean temperature of summer season. For the rest of months, MLR will be better than TLR because the lapse rate of temperature is not yet certain. The differences between the RMSE values of MLR-IDW and those of MLR-OK are slight.

\section{CONCLUSIONS}

In this article, the accuracy of three interpolator-performance error was evaluated. Our standpoints are illustrated through analyzing monthly mean temperature in Xinjiang Uygur Autonomous Region. It is very signify- 
Table 8. Characteristic of IDW, OK, TLR and MLR.

\begin{tabular}{cl}
\hline Methods & \multicolumn{1}{c}{ Characteristic } \\
\hline IDW $\begin{array}{l}\text { Strengths: fast, accurate, easy to apply, certainty interpolation, no special requirements. } \\
\text { Disadvantage: very simple, unable to estimate error in theory. }\end{array}$ \\
OK $\begin{array}{l}\text { Strengths: space statistical as its solid theoretical basis, can make estimation theory with point } \\
\text { by point, and won't produce boundary effect. } \\
\text { Disadvantage: slower, more calculation, the variograms is selected according to experience. }\end{array}$ \\
TLR $\begin{array}{l}\text { Strengths: consider the lapse rate, suitable for mountainous area. } \\
\text { Disadvantage: complex, unsuitable for plain area, large amount of calculation. }\end{array}$ \\
MLR $\begin{array}{l}\text { Strengths: small calculation, can make an overall estimate of error. } \\
\text { Disadvantage: must have good sampling design, complex to apply, large amount of calculation. }\end{array}$
\end{tabular}

cant and important to research the optimal spatial interpolation method for climate data in remote area with parse meteorological stations and complex topography. The monthly mean temperatures of these average stations are alternately spatially interpolated using three spatial-interpolation procedures. It is necessary to conduct regional regression analysis prior to spatial interpolation of monthly mean temperatures. This study has some conclusions as follows:

1) Through the quality assessment for meteorological data, many stations can be rejected because of missing data or short duration, thus some invalid data and unreasonable temporal sequence are filtered out. This procedure is necessary to ensure the quality of meteorological data and improve the accuracy of interpolation result.

2) The interpolated results and validation results indicate that the method of directly interpolate observed temperature (DIOT) is unsuitable for the study area.

3) For the study area, it is important to process the observed data by local regression model before the spatial interpolation. This procedure can improve the accuracy and the credibility of interpolated result.

4) For the interpolated result, the elevation difference between meteorological stations and corresponding SRTM-DEM is not a significant difference. It can ensure the temperature of meteorological stations is accordance with the measured value by using the elevation from SRTM-DEM, but the overall accuracy can be reduced. Reversely, because of the elevation difference between meteorological stations and corresponding SRTM-DEM, it cannot ensure the temperature of meteorological stations is accordance with the measured value by using the elevation from meteorological stations. However, it can improve the overall accuracy in general places without meteorological stations.

5) In this paper, we found no statistically significant difference among the MLR-IDW, MLR -OK, TLR-IDW and TLR-OK for the monthly mean temperature in thae same year. Consequently, the optimum spatial interpola- tion method of one climate factor may be not suitable for other climate factors in the same area or the same climate factor in different area. We should choose the suitable interpolation method according to the research area, climate factor, temporal sequence, scale, etc.

6) The effect factors on the select result of interpolated methods are including the geographic location and geomorphologic feature of study area, the number and distribution of sample, the accuracy requirement of result, the consideration of calculation speed and calculated amount, etc. this study proof once again that no one spatial interpolation method is the absolutely optimal method.

However, through comparing with other methods, the MLR-IDW is the optimum spatial interpolation method for the monthly mean temperature based on cross-validation. For the authors, the further work is to test the reliability of results and analyze the influence of measurement accuracy, density, distribution and spatial variability on the accuracy of the interpolation methods.

\section{ACKNOWLEDGEMENTS}

This research is supported by the Chinese National Natural Science Fund Project (40871177, 40830529). We also want to give our gratitude to the editors and the anonymous reviewers.

\section{REFERENCES}

[1] Willmott, C.J., Rowe, C. and Philpot, W. (1985) Smallcale climate maps: A sensitivity analysis of some common assumptions associated. The American Cartographer, 12, 5-16. doi:10.1559/152304085783914686

[2] Ishida, T. and Kawashima, S. (1993) Use of cokriging to estimate surface air temperature from elevation. Theoretical and Applied Climatology, 47, 147-157. doi:10.1007/BF00867447

[3] Willmott, C.J. and Matsuura, K. (1995) Smart interpolation of annually averaged air temperature in the United States. Journal of Applied Meteorology, 34, 2577-2586. doi:10.1175/1520-0450(1995)034<2577:SIOAAA $>2.0 . \mathrm{C}$ $\underline{\mathrm{O} ; 2}$

[4] Courault, D. and Monestiez, P. (1999) Spatial interpola- 
tion of air temperature according to atmospheric circulation patterns in southeast France. International Journal of Climatology, 19, 365-378. doi:10.1002/(SICI) 1097-0088(19990330)19:4<365::AID -JOC369>3.0.CO;2-E

[5] Price, D.T., McKenney, D.W., Nalder, I.A., Hutchinson, M. F. and Kesteven, J.L. (2000) A comparison of two statistical methods for spatial interpolation of Canadian monthly mean climate data. Agricultural and Forest Meteorology, 101, 81-94.

doi:10.1016/S0168-1923(99)00169-0

[6] Hofierka, J., Parajka, J., Mitasova, H. and Mitas, L. (2002) Multivariate interpolation of precipitation using regularized spline with tension. Transactions in GIS, 6, 135-150. doi:10.1111/1467-9671.00101

[7] Rawlins, M.A. and Willmott, C.J. (2003) Winter air temperature change over the terrestrial arctic, 1961-1990. Arctic, Antarctic, and Alpine Research, 35, 530-537. doi:10.1657/1523-0430(2003)035[0530:WATCOT]2.0.C $\mathrm{O} ; 2$

[8] Dobesch, H., Dumolard, P. and Dyras, I. (2007) Spatial interpolation for climate data: The use of GIS in climatology and meteorology. ISTE Ltd., London.

[9] Muhammad, W.A., Zhao, C., Ni, J. and Muhammad, A. (2010) GIS-based high-resolution spatial interpolation of precipitation in mountain-plain areas of Upper Pakistan for regional climate change impact studies. Theoretical and Applied Climatology, 99, 239-253. doi:10.1007/s00704-009-0140-y

[10] Şen, Z. and Şahin, A. D. (2001) Spatial interpolation and estimation of solar irradiation by cumulative semivariograms. Solar Energy, 71, 11-21. doi:10.1016/S0038-092X(01)00009-3

[11] Murphy, R.R., Curriero, F.C., Ball, W.P. and Asce, M. (2010) Comparison of spatial interpolation methods for water quality evaluation in the chesapeake bay. Journal of Environmental Engineering, 136, 160-171. doi:10.1061/(ASCE)EE.1943-7870.0000121

[12] Luo, W., Taylor, M.C. and Parker, S.R. (2008) A comparison of spatial interpolation methods to estimate continuous wind speed surfaces using irregularly distributed data from England and Wales. International Journal of Climatology, 28, 947-99. doi:10.1002/joc. 1583

[13] Janis, M.J., Hubbard, K.G. and Redmond, K.T. (2004) Station density strategy for monitoring long term climatic change in the contiguous United States. Journal of climate, 17, 151-162. doi: $10.1175 / 1520-0442(2004) 017<0151:$ SDSFML $>2.0 . C$ $\mathrm{O} ; 2$

[14] Kong, Y. and Tong, W. (2008) Spatial exploration and interpolation of the surface precipitation data. Geographical Research, 27, 1097-1108 (in Chinese).

[15] Abtew, W., Obeysekera, J. and Shih, G. (1993) Spatial analysis for monthly rainfall in South Florida. Water Resources Bulletin.American Water Resources Association, 29, 179-188. doi:10.1111/j.1752-1688.1993.tb03199.x

[16] Anderson, S. (2002) An evaluation of spatial interpolation methods on air temperature in Phoenix, AZ. Department of Geography, Arizona State University. http://www.cobblestoneconcepts.com/ucgis2summer/and erson/anderson.htm

[17] Daly, C., Helmer, E.H. and Quiñones, M. (2003) Map- ping the climate of Puerto Rico, Vieques and Culebra International Journal of Climatology, 23, 1359-1381. doi:10.1002/joc. 937

[18] Zhu, H., Liu, S. and Jia, S. (2004) Problems of the spatial interpolation of physical geographical elements. Geographical Research, 23, 425-432. (in Chinese)

[19] Li, M., Shao, Q. and Renzullo, L. (2010) Estimation and spatial interpolation of rainfall intensity distribution from the effective rate of precipitation. Stoch Environ Res Risk Assess, 24, 117-130. doi:10.1007/s00477-009-0305-3

[20] Chiu, C., Lin, P. and Lu, K. (2009). GIS-based tests for quality control of meteorological data and spatial interpolation of climate data-A case study in mountainous Taiwan. Mountain Research and Development, 29, 33949. doi: $10.1659 / \mathrm{mrd} .00030$

[21] Dodson, R. and Marks, D. (1997) Daily air temperature interpolated at high spatial resolution over a large mountainous region. Climate Resource, 8, 1-20. doi:10.3354/cr008001

[22] Dubois, G. (1998) Spatial interpolation comparison 97: Foreword and introduction. Journal of Geographic Information and Decision Analysis, 2, 1-11.

[23] Zimmerman, D., Pavlik, C., Ruggles, A. and Armstrong, M.P. (1999) An experimental comparison of ordinary and universal kriging and inverse distance weighting. Mathematical Geology, 31, 375-390. doi:10.1023/A:1007586507433

[24] Li, X., Cheng, G.D. and Lu, L. (2000) Comparison of spatial interpolation methods. Advance in Earth sciences, 15, 260-265 (in Chinese).

[25] Lin, Z., Mo, X., Li, H. and Li, H. (2002) Comparison of three spatial interpolation methods for climat variables in China. Acta Geographica Sinica, 57, 47-56 (in Chinese).

[26] Shi, Y.F., Shen, Y.P. and Hu, R.J. (2002) Preliminary study on signal, impact and foreground of climatic shaft from warm-dry to warm-wet in Northwest China. Journal of Glaciology and Geocryology, 24, 219-226 (in Chinese).

[27] Ishiyama, T. (2003) Estimation of surface conditions around oases in alluvial fan of Tarim Basin based on satellite data. Proceedings of the Third Symposium on Xinjiang Uyghur, China, 15-18.

[28] Fang, J.Y., Piao, S.L., He, J.S. and Ma, W.H. (2004) Increasing terrestrial vegetation activity in China, 19821999. Science in China Series C, Life Sciences, 47, 229240.

[29] Jia, B.Q., Zhang, Z.Q., Ci, L.J., Ren, Y.P., Pan, B.R., Zhang Z. (2004) Oasis land-use dynamics and its influence on the oasis environment in Xinjiang, China. Journal of Arid Environments, 56, 11-26. doi:10.1016/S0140-1963(03)00002-8

[30] Cheng W.M., Zhou C.H., Liu H.J., Zhang Y., Jiang Y., Zhang, Y.C. and Yao, Y.H. (2006) The oasis expansion and eco-environment change over the last 50 years in Manas River Valley, Xinjiang. Science in China (Series D), 49, 163-175. doi:10.1007/s11430-004-5348-1

[31] Shi, Y.F., Shen, Y.P., Kang, E., Li, D.L., Ding, Y.J., Zhang, G.W. and Hu, R.J. (2007) Recent and future climate change in Northwest China. Climatic Change, 80, 379-393. doi:10.1007/s10584-006-9121-7

[32] Qian, Y.B., Wu, Z.N., Yang, Q. Zhang, L.Y. and Wang, X.Y. (2007) Ground-surface conditions of sand-dust 
event occurrences in the southern Junggar Basin of Xinjiang, China. Journal of Arid Environments, 70, 49-62. doi:10.1016/j.jaridenv.2006.12.001

[33] Shen, Y.L. (2009) The social and environmental costs associated with water management practices in state environmental protection projects in Xinjiang, China. Environmental Science and Policy, 12, 970-980. doi:10.1016/j.envsci.2009.03.006

[34] Zhao, X., Tan, K., Zhao, S. and Fang, J. (2011) Changing climate affects vegetation growth in the arid region of the northwestern China. Journal of Arid Environments, 75, 946-952.

[35] Pan, Y.Z., Gong, D.Y., Deng, L., Li, J. and Gao, J. (2004) Smart distance searching-based and DEM-informed interpolation of surface air temperature in China. Acta Geographica Sinica, 59, 366-374 (in Chinese).

[36] Zhong, J. (2007) Method of spatial interpolation of air temperature based on GIS and RS in Xinjiang. Desert and Oasis Meteorology, 1, 33-35 (in Chinese).

[37] Zhong, J. (2010) Study on spatial precipitation interpolation precision based on GIS in Xinjiang. Arid Environmental Monitoring, 24, 43-46, 57 (in Chinese).

[38] He, Y., Fu, D., Zhao, Z., Su, J. and Lü, G. (2008) Analysis of spatial interpolation methods to precipitation based on GIS in Xinjiang. Research of Soil and Water Conservation, 15, 35-37 (in Chinese).

[39] Integrated Scientific Research Team of Xinjiang (ISRT),
CAS, The geography department of Beijing Normal University. (1978) Xinjiang Geomorphology. Science Press, Beijing (in Chinese).

[40] Daly, C. (2006) Guidelines for Assessing the Suitability of Spatial Climate Data Sets. International Journal of Climatology, 26, 707-721. doi:10.1002/joc. 1322

[41] Liao, S.B. and Li, Z.H. (2004) Some practical problems related to rasterization of air temperature. Meteorological Science and Technology, 32, 352-356 (in Chinese).

[42] Cressie Noel, A.C. (1993) Statistics for spatial data. Wiley-Interscience, New York.

[43] Yang, L.P. (1987) An Abstract for Comprehensive Geographical Regionalization in Xinjiang. Science Press, Beijing (in Chinese).

[44] You, S.C. and Li, J. (2005) Study on error and its pervasion of temperature estimation. Journal of natural resources, 20, 140-144 (in Chinese).

[45] Collins, F.C. (1996) A comparison of spatial interpolation techniques in temperature estimation. Proceedings of the Third International Conference/Workshop on Integrating GIS and Environmental Modeling, Santa Barbara, January 21-26. http://www.ncgia.ucsb.edu/conf/SANTA FE CD-ROM/ sf papers/collins fred/collins.html

[46] Myers, R.H. (1990) Classical and modern regression with applications. PWS-Kent Publishing, Boston. 